\title{
Perceived Life-Readiness from Real-World Curriculum Experiences of Alumni
}

\author{
Caterina Belle Azzarello ${ }^{1}$, Lee Arakawa ${ }^{1}$, Daniel Edi ${ }^{1}$, Madasyn Sutton ${ }^{1} \&$ Randy Larkins ${ }^{1}$ \\ ${ }^{1}$ University of Northern Colorado, United States \\ Correspondence: Caterina Belle Azzarello, University of Northern Colorado, United States.
}

Received: March 30, 2021

Accepted: June 1, 2021

Online Published: June 3, 2021

doi:10.5430/ijhe.v10n6p33

URL: https://doi.org/10.5430/ijhe.v10n6p33

\begin{abstract}
Students pursue college degrees expecting to learn skills necessary to navigate adult life. While this is the expectation of most students, there is a lack of research examining the perceived effectiveness of real-world applicability in undergraduate degrees.

Objective. The purpose of this phenomenological and constructivist study was to explore how college alumni perceive their educational experiences in terms of real-world preparedness.

Methods. Eight participants in their mid-twenties (5 females, 3 males) were selected using purposeful sampling. Participants participated in informal, semi-structured, one-on-one Zoom interviews and demographic questionnaire responses.

Results. Emerging themes indicated that alumni felt the relationships formed had a greater contribution to their life-readiness compared to their real-world curriculum. Other emerging themes revealed alumni believed they developed valuable skills through hands-on experience and group work. Recommendations were made by alumni for curriculum changes, including smaller class sizes and inclusion of more practical courses.

Conclusions. Based on these findings, future research should aim to replicate this study using a broader range of alumni to further investigate this phenomenon, as well as studies that investigate various college types and student experiences.
\end{abstract}

Keywords: real-world curriculum, higher education, skill acquisition, life skills, qualitative research, curriculum reform, career-readiness, experiential learning

\section{Introduction}

\subsection{Rationale}

The purpose of this qualitative study was to understand and describe self-perceived preparedness from real-world curriculum within higher education and then use it as action research to propose a curriculum reform. We were interested in studying how alumni perceive and describe their educational experiences in terms of preparing them for the real-world. This study involved the collection of existing information about the students' educational experiences by virtual interview to evaluate self-perceived real-world preparedness. The term "real-world curriculum" was coined by the researchers to describe a curriculum that is practical and whose aim is to prepare students for life after school by incorporating student-centered learning, collaborative inquiry, experiential learning, perspective taking, social critique, and multicultural emphases as suggested by Swaminathan (2007). Information is needed to validate the little existing research on real-world curriculum, especially within the framework of graduated college students. Furthermore, the utilization of the term real-world curriculum needs to be succinctly defined. It is important to discover whether the usually costly four-year educational system is effective for preparing those for the real world. Recent graduates have the memory and influence of what their college education has given them, which makes their perspective helpful for understanding the need for a real-world curriculum. As the world grows towards social independence and technological dependence, the need for life skills to ensure readiness for the real-world is evident. An example of this could be knowing and understanding the different themes in political ideologies so that voting is logically based.

\subsection{Background}

The increasing need for awareness and activism in society parallels the increasing need for challenging real-world applications within the college curriculum. There have been challenges for many decades surrounding racism, politics, 
and the development of the educational world (Hannan, 1987). As students, researchers and leaders in the community, we see the need for the improvement of teaching, curriculum construction and the surrounding real-world. This comes at a time where there is little existing research on real-world curriculum, and an increasing cost of education for the everyday American. Joyce and While (2020) argued that the new education must prepare our students to thrive in a world of flux, to be ready no matter what comes next. They also argued that it must empower them to be leaders of innovation and to be able not only to adapt to a changing world but also to change the world. In addition, the skills being gained on campus need to align with critical thinking, problem solving, collaboration, and innovation (Kivunja, 2015). This time needs to not only fulfill students educationally, but ought to foster an environment that provides the skills needed for handling day to day life challenges (Pring, 1987). In summation, real-world curriculum in schooling is necessary in helping American citizens prepare for life outside of school.

\subsection{Related Literature}

Failure to use a real-world curriculum design in universities may result in college graduates feeling underprepared when entering their career field. In exploring the importance of real-world learning in curriculum and its connection to employability, Calnon explains that,

Employers want students to have well-developed communications and analytical and critical thinking skills...to have practical experience before entering the world of work...signature learning experiences will enable students to apply classroom learning to real-life issues and problems, thus developing the skills and savvy that will equip them for success (Calnon, 2013).

Lopes also explains,

Human Resources Departments are constantly putting out job calls that seek people who can think creatively, work in teams, are collaborative and respect diversity... Let us not forget that colleges and universities are not just institutions of learning but are also employers". But it appears that many college graduates today are underprepared for the demands of stressful workplaces and that they also seem to lack the ability to establish healthy relationships with colleagues (Lopes, 2014).

As college become more normative for all students, the assumption lies that what is taught in school will be applicable to a real world job. There is a strong movement towards career readiness from college. In addition, there are trends that are placing accountability on colleges to update their curriculum and develop new resources for alumni (Darling-Hammond, Wilhoit, \& Pittenger, 2014).

In addition to four-year universities, community, liberal arts, and technical colleges are also struggling to teach real-world skills to their students. In exploring the need for such changes in the community college classroom, Joyce and White (2020) acknowledged that although community colleges are geared toward preparing their students to be ready for the workforce, communication skills are often underdeveloped in today's community college graduates. Communication is often categorized under those soft skills that are often not being taught in education, but according to Joyce and White (2020), when students learn to communicate effectively, starting in their learning communities, they take that confidence and skill into the workforce, but even more importantly, they take it out into the community.

With regards to liberal arts colleges, which are long on theory and intellectual development, but short on vocational or professional training (Belkin, 2018), liberal arts students may have differing opinions on curriculum goals from that of four-year university students. For example, the liberal arts cultivate intellectual agility and the ability to learn throughout your life (Belkin, 2018), rather than focusing on career-specific goals. On the other hand, the goals of technical colleges are to produce graduates for the world of work and to provide students with the opportunity to acquire specific job related skills at a level which would allow them to progress into an industry in their chosen field (Moswela \& Chiparo, 2015). Although the goals of technical colleges are directly related to preparing students for the professional world, they too, have faced challenges in doing so. According to Moswela and Chiparo (2015), there is a mismatch between the type of students produced and the expectations of the industry in terms of skills acquisition.

In a study conducted by G. Burch, F. Burch, Heller, and Batchelor (2015), researchers explored the application of what they define as a conception-focused curriculum in an undergraduate business statistics course of 125 students. This curriculum guided student learning by using conception learning and real-world problem solving, encouraged students to acknowledge that most situations have more than one single correct solution, and motivated them to use analytical and practical thinking while drawing on a diverse knowledge base (Burch et al., 2015). The results of this study showed that students involved in the conception-focused curriculum perceived themselves as being higher order learners and global citizens (Burch et al., 2015). 
The study by Burch et al. (2015), is just one of very few studies available that explore the concept of a real-world curriculum and students' perceived readiness for life after graduation. Because of this, there is an undeniable need for further research to provide students with useful knowledge and skills to prepare them to become successful employees in their specific career fields. Learning must have utility, which is often accomplished by linking learning to the world outside of school (Christ, 1995).

The literature has also demonstrated large movements toward emphasizing career-readiness in higher education, and toward requiring every college campus to incorporate experiential learning into the curriculum of each major. According to the National Association of Colleges and Employers (NACE) (2021), career readiness is defined as the "foundation from which to demonstrate...competencies that broadly prepare the college educated for success in the work place" (p. 1). The NACE explains that career readiness must be key for new college graduates in order to be successful in their careers, and that, "career readiness is...the new career currency" (National Association of Colleges and Employers, 2021, p. 1). A movement in higher education towards emphasizing career-readiness is also evident in the literature. Kijinski (2018) describes a "[current] popular movement on college campuses...of 'experiential learning'..." (p. 1), explaining that college students' curriculums are most in need of more real-world experiences, which would help students become more competent employees in their future careers. Increasing numbers of higher education institutes have been incorporating these experiential learning opportunities, emphasizing that each of their students has had "at least one "experiential learning' experience" (Kijinski, 2018, p. 1). For example, one of the State University of New York's (SUNY) main goals is to ensure each one of their students is exposed to at least one experiential learning opportunity before graduating (Kijinski, 2018).

\section{Theoretical Framework}

The two theories that were at the backbone of our research were phenomenology and constructivism. The purpose of this phenomenological and constructivist study was to explore how college alumni describe their self-described and perceived life-readiness from their experienced real-world curriculum. Phenomenology is mostly concerned with how human condition and perception influence our qualitative life moments. It can be argued that phenomenology will be at the forefront of all qualitative research because of its basic concern of human experience and the use of lived experiences towards application (Valentine, Kopcha, \& Vagle, 2018). Using imaginative variation, we [the researchers] were able to see the experience of post-college life from multiple angles, helping us build a more meaningful narrative surrounding this issue (Merriam \& Tisdell, n.d.). Phenomenological studies allow us to explore the "what it is like" for us graduates after college. In our study, we were interested in the experience of alumni when it comes to their perceived life-readiness from real-world curriculum. Phenomenology allows for subjective experiences to becomes reputable, quantifiable change. Applied constructivist research helped us aim to find the meaning behind real-world curriculum and helped us describe recently graduated US college students' perceived readiness. Constructivism allowed our participants to build a meaningful narrative about the real-world curriculum. Constructivism is defined as the view that all knowledge, and therefore all meaningful reality as such, is contingent upon human practices, being constructed in and out of interaction between human beings and their world and developed and transmitted within an essentially social context (Crotty, 1998). As researchers, we aimed to be both objective and subjective with our participants' data, for the truest narrative to become exposed. Since real-world curriculum has yet to be defined as a type of common practice succinctly, we used interview data to build meaning, so that there can be a unanimous definition for further research. The building of meaning to create a new construct is the fundamental basis of constructivism. Our researchers have come to the consensus that our degrees and goals both aligned and prepared us for research surrounding topics of educational improvement. The concentrations of our degrees are sports psychology, educational psychology, statistics and research methods, and curriculum creation. Our eclectic educational backgrounds allowed us to help note any potential biases, and the vast statistical knowledge helps ensure credibility and validity in our research methods. Our backgrounds are diverse enough that we were able to have a unique enough perspective to notice any inconsistencies within our work. We find that education is the best tool for change in our world. Our studies could inspire new designs for curriculums that are more focused on preparing those students after school ends. We all see the blatant need for improving teaching, curriculum and the surrounding real-world.

\section{Method}

\subsection{Participants}

Participants were adults over the age of 18 years who have graduated from a college or university in the United States within the past three years. Eight participants were initially sought using purposeful sampling. Maximum variation in the sample was sought, seeking participants from a variety of cultural backgrounds, ages, and genders in order to provide data that is more dense and descriptive of a wide variety of alumni experiences and to improve the 
trustworthiness of the research. We contacted possible participants through email to discuss the purpose of this study and their willingness to participate. In total we ended up interviewing eight participants (5 females, 3 males) all in their mid-twenties.

\subsection{Setting}

All interviews took place virtually via Zoom; thus, participants and researchers were not in the same location. The city and state of interviewees was asked within the demographic information questionnaire. Participants graduated from universities in the United States.

\subsection{Method for Data Collection}

To obtain an in-depth understanding of the case, we used informal, semi-structured interviews for data collection. The data collection included one-on-one Zoom interviews and demographic questionnaire responses. First, participants were asked to give their verbal consent form to help ensure they understand the purpose of the study and that they and anyone who was mentioned during the interview by the participants would remain confidential. Before the interview, participants were then asked to complete a questionnaire that provided information related to their undergraduate studies. Participants were given the opportunity to choose pseudonyms before interviews began. Next, the participants participated in an audio-recorded semi-structured interview in which they were asked seven structured questions with unstructured follow-up questions as necessary. A list of interview questions is included in Appendix A.

The interviews took place via zoom and lasted approximately one hour due to the nature of semi-structured questions. The data collected included demographic information, audio-recorded interview data, and transcriptions of the interviews. Interview questions were semi-structured to facilitate asking the participants the same questions to gather many-layered, intricate, and detailed data. Bernard (2012) noted that interview questions should be structured to facilitate asking multiple participants the same questions to be able to achieve data saturation. The use of the unstructured follow-up questions contributed to the richness of the data. Fusch and Ness (2015) noted that in phenomenological study design, the use of probing questions will assist researchers in their quest for data saturation. This study consisted of eight participants as it was more of a pilot study to help uncover new concepts. Data saturation may be attained by as little as six interviews depending on the sample size of the population (Guest, Bunce, \& Johnson, 2006). Although our population is very large as we are focusing on alumni in the United States, as stated by Dibley (2011), it's best to think of data saturation in terms of thick (quantity) and rich (quality), rather than in terms of the size of the sample as advocated by Burmeister and Aitken (2012). In-depth interviews are intensive, asking a small number of participants to elicit detailed information regarding the participants' perspectives (Boyce \& Neale, 2006). Vagle \& Hofsess (2016) harp on the need for reflexive action towards making meaningful changes within curriculum reform and other educational topics. Our one-on-one individual semi-structured interview allows for meaningful experiences to be revealed and the "what it is like" to become uncovered. Our sample consisted of participants who had different characteristics; they did their undergraduate studies in different fields, some had minors, some did a double major, some did go straight into graduate school while others went straight to the workplace. These different characteristics along with the depth of the interviews contributed to the achievement of data saturation.

\subsection{Trustworthiness}

To make sure this research was viewed as trustworthy, we attempted to ensure credibility, transferability, dependability, and confirmability of this research.

Credibility seeks to answer the question "How congruent are the findings with reality?" To ensure credibility, we first gathered credible data using purposeful sampling. We also used member checking and peer checking. We ensured that those participating in research were identified and described accurately. Every stage of the way was documented through our research journals. We also gave the opportunity to each participant to refuse to participate in the project to ensure that the data collection sessions involved only those who are genuinely willing to take part and share their experience frankly and truthfully. We asked participants to read the transcripts of the dialogues in which they have participated to make sure their words matched what they intended. Finally, we examined previous research findings to assess the degree to which the projects' results were congruent with those of past studies.

Transferability refers to the extent to which the results of a work at hand can be applied to a wider population. Using thick description allows the readers to "transfer information to other settings and to determine whether the findings can be transferred" (Creswell, 2013). Transferability also refers to the potential for extrapolation. It relies on the reasoning that findings can be generalized or transferred to other settings or groups. To ensure transferability, we made it our priority to state the principles and criteria used to select participants and detail the participants' main characteristics so that the transferability of the results to other contexts can be assessed (Moretti et al., 2011). 
Dependability refers to how similar the results obtained would be if the work were repeated, in the same context, with the same methods and with the same participants. Dependability also refers to the stability of data over time and under different conditions and it seeks to answer the question, "Would the findings of an inquiry be repeated if it were replicated with the same or similar participants in the same context?" (Lincoln \& Guba, 1985; Polit \& Beck, 2012). To ensure dependability, we made sure the processes within the study were reported in detail, enabling a future researcher to repeat the work. For this, we described what was planned and executed on a strategic level, i.e, research design and its implementation; to address the minutiae of what was done in the field, i.e, the operational detail of data gathering; and to evaluate the effectiveness of the process of inquiry undertaken. We also stated the principles and criteria used to select participants and detail the participants' main characteristics.

Confirmability deals with the question "How well the study does what it is designed to do?" (Merriam, 1995). Confirmability also refers to the objectivity of the study, the data's accuracy, relevance, or meaning. We wanted to ensure that both the findings of this study are confirmed by another and the link between the data and our interpretations. Clarifying our stance helped increase our study's confirmability. Lastly, we did a confirmability audit which examines the product to attest that the findings, interpretations \& recommendations are supported by data. Two researchers first summarized the study and analyzed the data, and the other two researchers went over the findings to make sure they were accurately describing the data. The findings of our study are generalizable to the extent that people reading the study feel it may be to their situation.

\subsection{Data Analysis}

We used thematic analysis. Braun and Clarke (2006) described the thematic analysis approach as an accessible and flexible method for identifying, analyzing, and reporting patterns (themes) within qualitative research data. The thematic analysis consists of six steps. The first step is the familiarization with the data and the generation of an initial list of ideas about what is in the data and is interesting about them. Then the assignment of preliminary codes to the data to describe the content (Step 2). Step 3 consists of searching for patterns or themes in the codes across the different interviews. The fourth step consists of reviewing themes that emerged. Those themes are then defined and named (Step 5) before the report is produced (step 6). The interview was transcribed from the audio recording and coded by the researchers.

\section{Results}

Through eight narratives obtained through virtual interviews, we were able to construct a reasonable understanding about real-world curriculums' role in the perceived success of recently graduated undergraduate students. Our demographic table (Table 1) provides valuable information about the nature of our subjects, and how that might influence our current and future research.

We had a diverse group of eight subjects regarding university type, university location, course of study, race, and interests. Our research question: How do alumni perceive higher education's real-world curriculum preparation for life-readiness? was revealed through seven interview questions that targeted critical thinking, technical skills, and soft skills. Participants were able to divulge their thoughts based on the interview questions asked. Since our theoretical stance has influence from constructivism, we allowed the eight narratives to display what was occurring within our higher educational system in America. We felt as though we were successful in creating a narrative about the real-world curriculum and defined both positive and negative issues surrounding it.

The researchers' consensus was that the participants' undergraduate careers were fruitful in preparing them for continuing education, such as learning statistical techniques or writing styles. Few of the participants were completely satisfied with their educational experience. For most participants, there were areas within their educational career that were lacking, such as the "real-world" aspect of life tasks; like making an important purchase (i.e. car or house), voting, or handling student loan debt. In addition, there seemed to be a need for improvement in engagement of interpersonal skills. Being able to communicate with instructors or get extra help on an assignment was a factor that was missing in some of the universities. Most universities can allow for autonomy and anonymity, which can lead to students getting lost within the student population or feeling like they cannot speak out for help. Some of our participants believed smaller class sizes with more dynamic and hands-on approaches would have been a benefit within their undergraduate studies. Figure 1 is just one example of the possible ways to organize the constructed narrative feedback that surround improvement in undergraduate studies programs. Most of our participants felt their undergraduate curriculum had some real-world aspects to it. For example, they mentioned classes like statistics, business, writing, and hands on laboratory experience. 


\section{Discussion}

After data from the interviews was collected, participants' transcripts were reviewed several times to establish the major themes of the participants' experiences. From each transcript, significant phrases or sentences that pertain directly to alumni's experiences of their real-world curriculum were identified. Meanings were then formulated from the significant statements and phrases. Researchers coded each transcript by assigning specific colors to each theme. The formulated meanings were clustered into themes allowing for the emergence of themes common to all of the participants' transcripts. This resulted in 10 themes.

\section{1) Transition into work and/or grad school}

Our results demonstrated that four of the eight participants experienced a smooth transition from undergraduate school into their current job, and two of the eight participants experienced smooth transitions from undergraduate to graduate school. Kalei, who majored in Human Resources Management stated,

My transition was pretty smooth. I had a job coming out of college, and throughout my last year of college...I think it was different having to go to work and learn about how payroll and stuff works and how you're taxed. The classes I took gave me the tools I needed to be able to do my current job.

Another participant, Morgan, who majored in Psychology with minor in Business administration stated,

I'm actually in graduate school now, so I would say the transition was fairly easy because I went from school to school.

Two of the eight participants did not experience smooth transitions from undergraduate to graduate school due to change of major. Our participant, Jaya, who majored in Petroleum Engineering with minors in Economics and Mathematics stated,

Because my master was in economics applied to energy, what I learned in school was not directly related. The curriculum for petroleum engineering, I don't think that I used that.

2) Skills acquired through hands on experience

Regarding critical thinking skills, four of the eight participants stated that doing their own analysis and research allowed them to acquire skills for collecting data, analyzing data, and critically reading articles. In regard to soft skills, seven of the eight stated that doing group projects taught them to work effectively with partners, and be team players, and two of the eight learned how to communicate effectively and professionally. One participant, Nicky, who majored in Biology with a minor in chemistry, talking about how he acquired his skills, stated,

Just working with people in the lab...doing research...having partners and being able to communicate effectively...show things like...people skills [and] analysis skills.

3) Skills acquired through specific courses

Within this theme, five of our eight participants stated they developed technical skills from courses taught in school such as finance, statistical software, and strategy development courses. Jordan, who majored in Business Administration and Marketing with minors in Economics and Global Management stated,

In my statistics classes, we had to use different statistical software to solve questions. That's kind of the biggest technical skill that I learned.

4) Skills naturally developed

Regarding critical thinking skills, soft skills, and technical skills, two of our eight participants stated they developed some of these skills naturally through maturation and personal experience. Participant Kyung, who and majored in Psychological sciences stated,

I think maturing by nature while I've been getting older...I think [critical thinking, soft, and technical skills] has come with it.

5) Skills acquired through internship, and/or mentorship

In addition to some skills being developed naturally through maturation, two of the eight participants stated that they developed their soft skills primarily through their work as a TA (teaching assistant), RA (resident assistant), or intern. Participant Kalei stated,

I definitely had a teacher like...that would really preach on how to be seen as an asset to an employer, and how to move up in your career, and so on, and so forth. 
6) Change of curriculum by removing courses

When asked how they would change their undergraduate curriculum, three of our eight participants stated they would remove the general education, "unrelated", and elective courses, and instead begin with courses specific to the students' major. Jaya stated,

I took a biology class, and for me personally, I don't think it was necessary for my field. So that's the first class I would remove from the curriculum.

7) Change of curriculum by adding certain courses

When asked how participants would change their undergraduate curriculum, the other five of the eight stated they would add more practical courses that teach life skills such as doing taxes, investing, resume building, personal finance courses, home-buying, etc., and two participants explained they would add more classes providing hands-on experiences. Kalei stated,

I would probably switch [general education courses] out for...things like...how to do your tax return or...how to do financing or...learning how to invest in the market.

Participant Jaya stated,

Curriculum needs to be updated in a way that it gives students the current market of their fields. Second, the curriculum should aim to help students develop skills that are valuable in their fields.

Kens, a participant who majored in Kinesiology \& Health Promotion stated,

If I could design my own curriculum, I would add a more in-depth classes to myundergraduate program that details palpation of muscles and other anatomical structures. This would have greatly added to my transition to PT school.

8) Curriculum is okay the way it is

Of the eight participants, only one stated they wouldn't change much about their undergraduate curriculum, and in fact enjoyed the challenge of the more difficult courses other students may consider irrelevant to their degree. This participant, Nicky stated,

Honestly, I don't see anything missing. Everything [necessary] is pretty much there... I feel like [the difficult] courses gave me the strength, you know, with the perseverance, they gave me the discipline to just keep going.

9) Attribution of life readiness to curriculum

Out of all eight participants, only one attributed the majority of their life-readiness to their undergraduate curriculum. Participant Kens,

I attribute most of my ability to transition into my career to real-world curriculum. Without this approach to my curriculum, I would not have developed the evaluation and treatment skills needed for my career.

Of the eight participants, two felt that only a small percentage of their life readiness was attributed to their undergraduate curriculum, feeling a "disconnect" between school and their job. One participant, Jordan, attributed only $50-60 \%$ of their life-readiness to their undergraduate curriculum, while the other participant stated they felt only about $30 \%$ of their undergraduate curriculum prepared them for the real-world.

10) Attributing life readiness to relationships formed in college

Although some participants felt their undergraduate curriculum did not provide real-world courses, and therefore did not properly prepare them for the transition into their career, they did, however, believe the interpersonal and professional relationships they formed did. Jordan stated,

I'd say the courses didn't prepare me for my current stage of life, but rather the people I met through being at college helped prepare me. I met those people through the way of conferences and on-campus jobs.

\section{Conclusion and Recommendations for Future Research}

Throughout the analysis and literature study, we were able to find evidence that suggests that there needs to be some changes in the current American educational system. In addition, the narratives suggest that there needs to be more research done surrounding this topic, from a wider participatory pool. Nevertheless, our general hypothesis that there was improvement needed was supported through the narratives of our 8 participants. Throughout the 8 narratives, 10 common themes were able to emerge and shed light on a very important topic that concerns a large proportion of American citizens. "The assumption is that such "real-world" experiences will help students build identities as 
competent and engaged participants in communities of practice beyond the classroom" (Swaminathan, 2007). The cost that surrounds our educational system ought to ensure that the needs of each student are cared for, and they feel properly prepared to deal with the real-world. Implementing more real-world courses into the higher education curriculum will not only improve student relations, it will help prepare generations of Americans to make well informed decisions and handle the stressors of American life better. With that, there is still more research to be done to ensure the external validity of our experiment.

In the future, there ought to be multiple studies that use the method of interviewing, in conjunction with physical records to help increase validity of the experiences presented. By multiple studies, we mean an eclectic variation of studies that include a variety of universities and community colleges across the United States. The population samples ought to be diverse and having more studies will increase the sample size, therefore increasing the external validity of the research. An additional idea for future research would be to include students who did not graduate and move onto graduate school, or directly into a stable income job. Most of our participants identified as being stable because of the actuality of their next step after graduation. More participants need to be interviewed with an eclectic post-bachelor's experience.

This qualitative constructivist study helped us understand and describe the self-perceived preparedness from real-world curriculum within higher education. We were able to divulge information surrounding courses, interpersonal relations, and financial strain. Ensuring that the students who attend the very costly universities within America are getting completely fulfilled. Utilizing this article, and any subsequent research that pertains to this issue, as action research to propose a curriculum reform for American universities is highly recommended.

\section{Acknowledgement}

We would like to acknowledge the University of Northern Colorado for allowing us to facilitate this research. In addition, we recognize the long history of Native peoples and nations that lived and stewarded the land where the university now resides and thank them and the land for allowing our research to be conducted there.

\section{References}

Belkin, D. (2018). Northeast rules in WSJ/THE ranking of liberal-arts schools; The highest-ranked liberal-arts colleges largely fit the stereotype: They're small, private, pricey and rural. Wall Street Journal.

Bernard, R. H. (2012). Social research methods: Qualitative and quantitative approaches (2nd eds.). Thousand Oaks, CA: Sage.

Boyce, C., \& Neale, P. (2006). Conducting in-depth interviews: A guide for designing and conducting in-depth interviews for evaluation input. Watertown, MA: Pathfinder.

Braun, V., \& Clarke, V. (2006). Using thematic analysis in psychology. Qualitative Research in Psychology, 3, 77-101. https://doi.org/10.1191/1478088706qp063oa

Burch, G. F., Burch, J. J., Heller, N. A., \& Batchelor, J. H. (2015). An empirical investigation of the conception focused curriculum: The importance of introducing undergraduate business statistics students to the "real world." Decision Sciences Journal of Innovative Education, 13(3), 485-512. https://doi.org/10.1111/dsji.12074

Burmeister, E., \& Aitken, L. M. (2012). Sample size: How many is enough? Australian Critical Care, 25, 271-274. http://doi:10.1016/j.aucc.2012.07.002

Calnon, A. (2013). Curriculum requires real-world learning. University Wire.

Christ, G. M. (1995). Curriculum with real-world connections. Texas Association for Supervision Curriculum Development, 52(8).

Creswell, J. W., \& Creswell, J. W. (2013). Qualitative inquiry \& research design: Choosing among five approaches, 152.

Crotty, M. (1998). Constructionism: The making of meaning. The foundations of social research: Meaning and perspective in the research process (pp. 53-77). London: Sage.

Darling-Hammond, L., Wilhoit, G., \& Pittenger, L. (2014). Accountability for college and career readiness: Developing a new paradigm. education policy analysis archives, 22, 86. https://doi.org/10.14507/epaa.v22n86.2014

Dibley, L. (2011). Analysing narrative data using McCormack's Lenses. Nurse researcher, 18(3). https://doi.org/10.7748/nr2011.04.18.3.13.c8458 
Fusch, P. I., \& Ness, L. R. (2015). Are we there yet? Data saturation in qualitative research. The qualitative report, 20(9), 1408. https://doi.org/10.46743/2160-3715/2015.2281

Guest, G., Bunce, A., \& Johnson, L. (2006). How many interviews are enough? An experiment with data saturation and variability. Field Methods, 18(1), 59-82. https://doi.org/10.1177/1525822X05279903

Hannan, A. (1987). Racism, Politics and the Curriculum. British Journal of Sociology of Education, 8(2), 119-133. https://doi.org/10.1080/0142569870080202

Joyce, D., \& White, N. M. (2020). Colleges need a makeover: Adapting to change one class at a time. Journal of Higher Education Theory and Practice, 20(5). https://doi.org/10.33423/jhetp.v20i5.3032

Kijinski, J. (2018). On 'experiential learning'. Inside Higher Ed. https://www.insidehighered.com/views/2018/01/08/why-experiential-learning-often-isnt-good-classroom-learni ng-opinion.

Kivunja, C. (2015). Teaching students to learn and to work well with 21st century skills: Unpacking the career and life skills domain of the new learning paradigm. International Journal of Higher Education, 4(1), 1-11. https://doi.org/10.5430/ijhe.v4n1p1

Lincoln, S. Y., \& Guba, E. G. (1985). Naturalistic inquiry. Thousand Oaks, CA: Sage. https://doi.org/10.1016/0147-1767(85)90062-8

Lopes, T. (2014). Creating Curricula for "Real World" Challenges. ProQuest, 19(3).

Merriam, S. B., \& Tisdell, E. J. (n.d.). Qualitative research.

Moretti, F., van Vliet, L., Bensing, J., Deledda, G., Mazzi, M., Rimondini, M., \& Fletcher, I. (2011). A standardized approach to qualitative content analysis of focus group discussions from different countries. Patient Education \& Counseling, 82, 420-428. https://doi.org/10.1016/j.pec.2011.01.005

National Association of Colleges and Employers. (2021). What is career readiness? NACE Center. https://www.naceweb.org/career-readiness/competencies/career-readiness-defined/

Polit, D. F., \& Beck, C. T. (2012). Nursing research: Principles and methods. Philadelphia, PA: Lippincott Williams \& Wilkins.

Pring, R. (1987). The Curriculum and the New Vocationalism. British Journal of Education and Work, 1(3), 133-148. https://doi.org/10.1080/0269000870010301

Stutey, D. M., Givens, J., Cureton, J. L., \& Henderson, A. J. (2020). The practice of bridling: Maintaining openness in phenomenological research. The Journal of Humanistic Counseling, 59, 144-156. https://doi.org/10.1002/johc.12135

Swaminathan, R. (2007). Educating for the "real world": The hidden curriculum of community service-learning. Equity and Excellence in Education, 40(2), 134-143. https://doi.org/10.1080/10665680701246450

Vagle, M. D., \& Hofsess, B. A. (2016). Entangling a post-reflexivity through post-intentional phenomenology. Qualitative Inquiry, 22(5), 334-344. https://doi.org/10.1177/1077800415615617

Valentine, K. D., Kopcha, T. J., \& Vagle, M. D. (2018). Phenomenological methodologies in the field of educational communications and technology. TechTrends, 62(5), 462-472. https://doi.org/10.1007/s11528-018-0317-2 


\section{Appendix A}

\section{Demographics:}

1. Where did you get your undergraduate degree?

2. What year did you graduate?

3. What was your major?

4. Did you have any minor?

5. Where do you currently live?

6. At what age did you complete your undergraduate studies?

7. List the organizations you were part of during your undergraduate studies.

8. Ethnicity

9. Marital status

\section{Interview questions: (7 Questions)}

1. How was the transition from college to your current stage of life? Do you feel like the courses you took in college prepared you enough for this current stage?

2. Define real-world curriculum (interviewer). Tell us about a class or instance that you were able to apply real-world curriculum to a real-life scenario.

3. What are some critical thinking skills you developed during your undergraduate studies that you find valuable? How did you develop those skills?

4. What are some technical skills you developed during your undergraduate studies that you find valuable? How did you develop those skills?

5. What are some soft skills you developed during your undergraduate studies that you find valuable? How did you develop those skills?

6. If you could design your own college curriculum, how different will that be from the one you had in college? What will you add and remove from it?

7. How much of your perceived life-readiness do you attribute to real-world curriculum? 


\section{Appendix B}

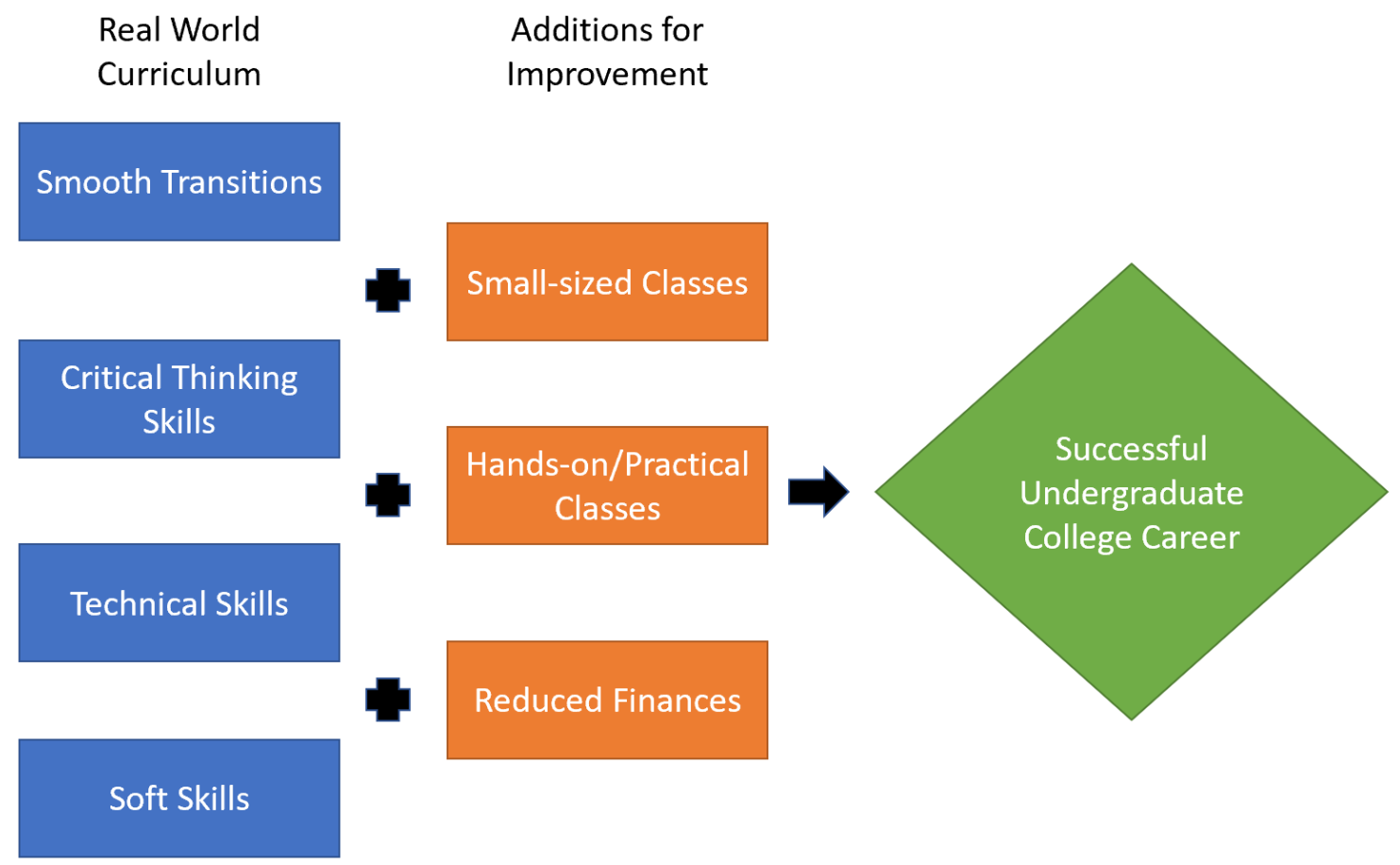

Figure 1. 


\section{Appendix C}

Table 1.

\begin{tabular}{|c|c|c|c|c|c|c|}
\hline $\begin{array}{l}\text { Participant } \\
\text { ID }\end{array}$ & $\begin{array}{l}\text { Graduation } \\
\text { Year }\end{array}$ & Major & Minor & $\begin{array}{l}\text { Age at } \\
\text { Grad. }\end{array}$ & Ethnicity & Marital status \\
\hline \multirow[t]{2}{*}{1} & 2018 & Human Resources & None & 22 & Asian & Single \\
\hline & & Management & & & & \\
\hline 2 & 2019 & Biology & Chemistry & 21 & African American & Single \\
\hline 3 & $2018 \& 2019$ & $\begin{array}{l}\text { Biology, Physiology, } \\
\text { Chemistry, Honors }\end{array}$ & $\begin{array}{l}\text { Zoology, Psychology, } \\
\text { Neuroscience }\end{array}$ & 23 & Caucasian & Single \\
\hline 4 & 2017 & $\begin{array}{l}\text { Kinesiology \& Health } \\
\text { Promotion }\end{array}$ & None & 22 & Caucasian & Engaged \\
\hline 5 & 2017 & Petroleum Engineering & Economics, Mathematics & 23 & Black African & Single \\
\hline 6 & 2016 & $\begin{array}{l}\text { Business Management, } \\
\text { Marketing }\end{array}$ & $\begin{array}{l}\text { Economics, Global } \\
\text { Management }\end{array}$ & $\begin{array}{l}\text { A week } \\
\text { from } 21\end{array}$ & White & Single \\
\hline 7 & 2018 & Psychological Science & None & 22 & Caucasian & $\begin{array}{l}\text { Single/Never } \\
\text { Married }\end{array}$ \\
\hline 8 & 2020 & Psychology & Business Administration & 24 & White/Caucasian & Never Married \\
\hline
\end{tabular}

\section{Copyrights}

Copyright for this article is retained by the author(s), with first publication rights granted to the journal.

This is an open-access article distributed under the terms and conditions of the Creative Commons Attribution license (http://creativecommons.org/licenses/by/4.0/). 